\title{
Copyright y derechos de autor en la Revista Española de Podología
}

Copyright in Revista Española de Podología

Copyright, cuya traducción literal es 'derechos de copia', hace referencia a los derechos que protegen la propiedad intelectual, artística o literaria, de un autor sobre la obra que ha creado. Se expresa mediante el símbolo "(C)" y abarca un conjunto de normas legales que amparan a los autores, tanto en términos morales (reconocimiento de la autoría) como en términos patrimoniales (reconocimiento de derechos de explotación) respecto de sus obras. Dicho de otro modo, el copyright garantiza el reconocimiento de la propiedad intelectual de un autor y, de esa manera, concede y protege los derechos exclusivos para la explotación comercial, la divulgación, reproducción, así como otros derechos de la propiedad intelectual relacionados con ella. La literatura científica no es una excepción y las leyes de copyright confieren automáticamente al autor los derechos exclusivos sobre sus artículos en el momento en que son escritos. Sin embargo, para que el artículo pueda ser publicado, la mayoría de las revistas científicas obligan a los autores a transferir estos derechos de forma exclusiva a las sociedades científicas o a las compañías editoriales por medio de Copyright Transfer Agreements, en los que los autores ceden todos sus privilegios, incluyendo generalmente la explotación comercial, la divulgación, reproducción o creación de obras derivadas a partir de su artículo.

En los últimos años este modelo de comportamiento y/o negocio ha comenzado a replantearse dentro de la comunidad científica. Por un lado, la irrupción del movimiento Open Access en las revistas científicas ha promovido el uso de licencias tipo Creative Commons, como es el caso de Revista Española de Podología, que se basan en la idea de que el derecho del copyright no ayuda a la hora de conseguir la correcta distribución de los artículos y que, de hecho, la gran mayoría de los autores en las publicaciones científicas no desean ejercer todos los derechos de propiedad intelectual que la ley les atribuye. Este tipo de licencias permite difusión en abierto de sus artículos y deja inútiles las leyes del copyright desde el punto de vista de los derechos de explotación. Por otro lado, el progreso actual de la ciencia ha derivado en el uso de tecnologías basadas en el metanálisis de diversos estudios, e incluso Big Data. Estas técnicas necesitan volver a utilizar y reanalizar los datos de investigaciones previas con la idea de obtener resultados más sólidos. El uso de los datos de estos artículos para realizar estas técnicas de metanálisis es un uso derivado de la obra que no está contemplado en las mayoría de las leyes de copyright.

Para el progreso real de la ciencia es absolutamente esencial que los datos obtenidos en una investigación concreta puedan ser diseminados libremente en foros científicos como congresos, jornadas e incluso en las propias universidades, y a su vez puedan ser utilizados para la creación de trabajos de metanálisis, o rebatidos o discutidos en otros estudios. Revista Española de Podología es consciente de este problema, y en el segundo número de 2019 cambió su política de copyright para los artículos publicados dentro de la revista. A partir de esa fecha, el autor o los autores han mantenido el copyright de su artículo publicado, conservando así los todos derechos intelectuales y patrimoniales sobre su artículo sin transferencia de los derechos de copyright, como anteriormente se venía haciendo. Este cambio se mantendrá en el futuro en Revista Española de Podología y los artículos se seguirán publicando con una licencia de publicación de Creative Commons (CC Reconocimiento 4.0 Internacional - www.creativecommons.org/licenses/by/4.0/) tal y como se viene haciendo desde 2016.

Un saludo, Redactor Jefe de Revista Española de Podología 